\title{
Online auction marketplaces as a global pathway for aquatic invasive species
}

\author{
Julian D. Olden (iD $\cdot$ Ethen Whattam $\cdot$ Spencer A. Wood
}

Received: 9 June 2020/Revised: 14 August 2020/Accepted: 5 September 2020/Published online: 17 September 2020

(C) Springer Nature Switzerland AG 2020

\begin{abstract}
The ornamental aquarium pet trade is a leading pathway for the introduction of aquatic invasive species. In addition to purchasing live organisms in stores, hobbyists are engaging more with alternative informal online marketplaces that enable peer-to-peer selling of aquarium organisms via auctions. Although growing in popularity, little is known regarding the global extent of informal marketplaces, including the taxonomy of species that are traded, their economic value, and the geographic routes by which live organisms are transported. In this study we use an automated web crawler to collect data on completed auctions between 2011 and 2017 from the largest informal market for aquarium hobbyists, AquaBid, to understand the market dynamics and trade flows of the
\end{abstract}

Guest editors: Katya E. Kovalenko, Fernando M. Pelicice, Lee B. Kats, Jonne Kotta \& Sidinei M. Thomaz / Aquatic Invasive Species III

Electronic supplementary material The online version of this article (https://doi.org/10.1007/s10750-020-04407-7) contains supplementary material, which is available to authorized users.

J. D. Olden $(\bowtie) \cdot$ E. Whattam

School of Aquatic and Fishery Sciences, University of

Washington, Seattle, WA, USA

e-mail: olden@uw.edu

S. A. Wood

eScience Institute, University of Washington, Seattle, WA, USA informal retail market online. During the 7-year study period, the AquaBid website facilitated the estimated trade of 539,548 live freshwater animals, 579,700 fish eggs, and 31,431 plant assortments/bunches among 24,409 unique users who collectively placed 444,132 bids on 192,227 auctions, representing a total sale value of \$6,015,030 USD. Source (seller) and recipient (buyer) locations of live organisms were distributed across 39 countries but concentrated largely in major cities of the United States and select European and southeast Asian countries. Our study is among the first to quantify geographic routes of live organism transport between specific locations on the landscape and demonstrates the highly diffuse and non-centralized nature of the informal aquarium trade. Evaluating the emerging challenges represented by informal online retail marketplaces is critical to create policy and regulatory solutions that minimize the transport of prohibited invasive species.

Keywords Biological invasions - Globalization - eCommerce Aquarium trade

\section{Introduction}

Developing effective strategies to prevent the ecological and economic impacts of harmful invasive species is considered fundamental in national-level policies 
(Early et al., 2016; Turbelin et al., 2017). Global trade and the associated movement of live organisms represent well-recognized pathways for biological invasions (Hulme, 2009). The ornamental aquarium pet trade has emerged as a leading pathway for the introduction of aquatic invasive species (Cohen et al., 2007; Chan et al., 2019; Lockwood et al., 2019), where numerous species have the opportunity to become established in foreign waters primarily through the release of unwanted organisms by pet owners (Padilla \& Williams, 2004; Rixon et al., 2005; Weigle et al., 2005; Gertzen et al., 2008; Chang et al., 2009; Strecker et al., 2011; Maceda-Veiga et al., 2013; $\mathrm{Ng}$ et al., 2016). Indeed, some of the most popular crayfish and fish sold are also the most likely to become established in the wild (Duggan et al., 2006; Chucholl, 2013; Magalhães \& Jacobi, 2017). Although the acquisition of live organisms was traditionally facilitated by multinational and local "brick-and-mortar" pet stores, these transactions are increasingly shifting to also include online marketplaces. This rise has been particularly prominent since the start of the COVID19 pandemic in 2020.

Global electronic commerce, or e-commerce, in the ornamental aquarium trade is quickly changing the ways that organisms are bought and sold through a diverse network of online marketplaces (Walters et al., 2006; Magalhães \& Jacobi, 2010; Humair et al., 2015; Mazza et al., 2015). These online marketplaces provide access to a diversity of nonnative species that fulfill aquarists' and consumers' changing attitudes towards more convenient purchasing and the acquisition of unusual pets for their aquarium (Humair et al., 2014; Marchio, 2018; Prokop \& Randler, 2018; Stringham \& Lockwood, 2018). A variety of formal and informal marketplaces have been created to meet the demand for ornamental aquarium species. Major multinational (i.e., Petco, Petsmart) and local pet stores have followed this trend by shifting portions of their live organism sales online to create a formal web marketplace where transactions occur between a business and a consumer (American Pet Products Association, APPA, 2017). Increasingly, hobbyists participating in the ornamental aquarium trade are also engaging in alternative informal online marketplaces that enables peer-to-peer selling of aquarium organisms (Humair et al., 2015).

The growth of informal retail marketplaces is providing a new and potentially diverse pathway for the movement of nonnative aquarium organisms. This retail market is centered around large online auction sites, and niche web businesses that attract hobbyists wanting to purchase specific species (Magalhães \& Jacobi, 2013; Humair et al., 2015; Mazza et al., 2015). Some brief explorations of these informal marketplaces have revealed a broad selection of nonnative species available for purchase (Kay \& Hoyle, 2001; Padilla \& Williams, 2004; Chucholl, 2013; Magalhães et al., 2017). According to studies of the online auction site, eBay, more invasive than nonnative plants were available to customers in the United States, and in Italy, 95\% of all aquatic species surveyed online were foreign to the country (Humair et al., 2015; Mazza et al., 2015).

Informal retail markets allow buyers to conveniently purchase organisms from peers around the globe. This may support novel long-distance dispersal pathways and elevate the potential of nonnative organisms to be introduced into new habitats (Maki \& Galatowitsch, 2004; Giltrap et al., 2009; Lenda et al., 2014). This risk is minimized in physical "brickand-mortar" stores and formal online marketplaces where regulations require businesses to apply and pay for licenses in order to sell and ship aquatic species (Invasive Species Advisory Committee, ISAC, 2012). Informal marketplaces also foster an environment where sellers can purposefully, or unknowingly, evade regulations through falsifying documents and utilizing transshipments (i.e., shipment of goods or containers to an intermediate destination, then to another destination) of nonnative or prohibited species. Pursuing these sellers and evaluating the online informal marketplace has been a time-consuming and expensive task for law enforcement and regulatory agencies (ISAC, 2012).

Due to rapid growth in online trade in live organisms, many countries have identified informal retail marketplaces as a significant risk to their biosecurity (Derraik \& Phillips, 2010; Martin \& Coetzee, 2011; Kikillus et al., 2012; Magalhães et al., 2017). Yet, numerous gaps exist in our understanding of this rapidly expanding sector of e-commence. Previous studies have mostly focused on a snapshot of listings present on informal marketplaces at one point in time and have been unable to determine whether transactions (not just postings) occurred (Papavlasopoulou et al., 2014; Humair et al., 2015; Mazza et al., 2015). This paper seeks to provide 
new insight into the informal marketplace for ornamental aquarium fishes by evaluating the global extent and economics of completed auctions of the largest online auction site dedicated to the aquarium hobby, AquaBid (www.aquabid.com). By systematically crawling the entire auction website, we evaluate the volume and value of transactions occurring over a 7-year period. Next, we construct trade flows illustrating the geographic locations of donors (sellers) and recipients (buyers) of live organisms in the marketplace. Findings from this paper provide new insight into the rapidly growing informal online retail market for the sale of ornamental aquarium species.

\section{Methods}

\section{Data collection}

We examined all completed auctions on AquaBid.com occurring over a 7-year period from January 1, 2011 to December 31, 2017. AquaBid is an auction marketplace created in 2000 to allow individuals, collectors, and breeders to buy and sell live aquatic organisms in an online community. We investigated AquaBid due to its high popularity among aquaria enthusiasts ( $>1.75 \mathrm{M}$ page-views/month), and the diversity of freshwater plants and animal species available for sale. Descriptions and photos of live organisms for sale are posted with additional information such as starting and current bid amount, auction timeline, and shipping options and costs (Fig. 1). AquaBid is different from other e-commence websites in that users can also post requests for live organisms wanted, for which sellers can respond. There is no charge to bid on an item, currently, but all sellers and buyers are required to register by providing a username and contact information. During the time of registration users are notified that the IP address of their computer is being recorded.

We programmed a web crawler to systematically read every auction listed on the AquaBid website and store data associated with auctions involving live ornamental organisms completed during the 7-year study period. The crawler, which was written in the python programming language, downloaded the content of each webpage by mimicking a standard desktop web browsing client using functions from the requests and urllib modules. Auctions were discovered by examining every known seller's list of closed auctions. As additional AquaBid users were found to be bidders and buyers on closed auctions, the browser iteratively searched each users' list of previous sales, and then any users found as buyers within. The crawler ran from June 17 to July 28, 2018, at which point there were no additional users or auctions to be cataloged. Each auction listing webpage was parsed, and we stored the following: auction ID, taxonomic group of the listed species, buyer and seller username, the seller's location (latitude and longitude), date of the completed auction, and the number of bids and final selling price (Fig. 1). Only 110 auctions (0.05\%) involved marine organisms, which were omitted from all subsequent analyses. Although the user-reported taxonomic ID field in the auction descriptions was extremely coarse, we were able to use this information to assign the organisms of each auction into 1 of 41 categories related predominantly to taxonomic affiliation and/or species native range.

\section{Data analysis}

We tabulated the number of auctions by taxonomic category and final sale price (USD) of all completed auctions. Sale prices were not adjusted for inflation given the limited time period examined. The total quantity of individuals was inconsistently reported in auctions. Therefore, each animal auction was conservatively assumed to involve a single individual, with the exception of "various mixed lot fishes", "snails", "invertebrates" (mainly shrimp), and "killifish eggs", which were each estimated to contain 10, 20, 20 and 25 individuals/eggs, respectively, according to commonly reported numbers in auction listings. Plants were sold by assortments or bunches and were inconsistently reported as numbers of trimmings/roots or volume (oz, cups, gallons); thus, we conservatively report plants by the number of auctions.

We analyzed the geography of live organism trade by examining those auctions that occurred between people who acted as both sellers and buyers at some point during the study period (2,283 users). Data filtering was necessary because only the locations of sellers are disclosed on auction listings. This filtering process resulted in the inclusion of $23 \%(n=37,727)$ of all auctions. Buyer and seller information was used to trace routes of live organism transactions between continents, countries, and regions of the US by using 


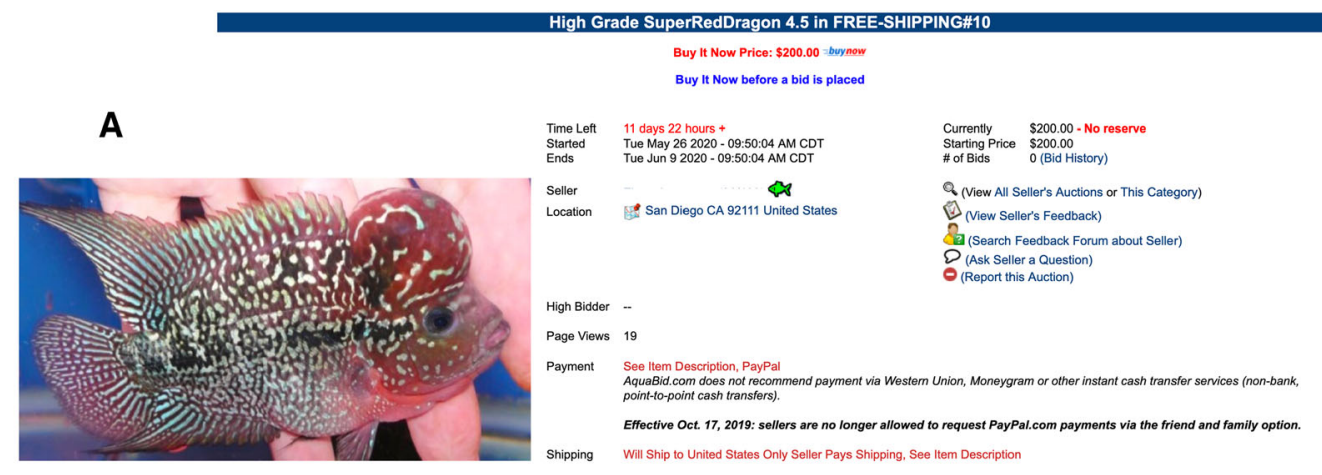

Seller assumes all responsibility for listing this item. You should contact the seller to resolve any questions before bidding. Currency is U.S. dollars (US\$).

It Like 0 Y Tweot Pinlt $51 K+$

Hello everyone! I have a unique King Super Red Dragon Flowerhom Male 4 " to 4.5 inches \#10.It's Up forbid or buys now for $\$ 200$ FREE FedEx Express ovemight shipping available

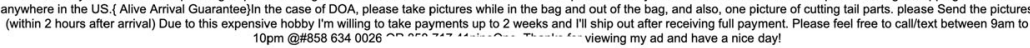

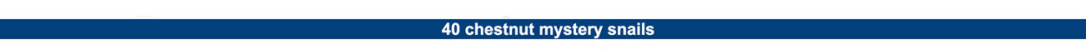

Buy It Now Price: $\$ 30.00$ buynow

Buy it Now before a bid is placed

B

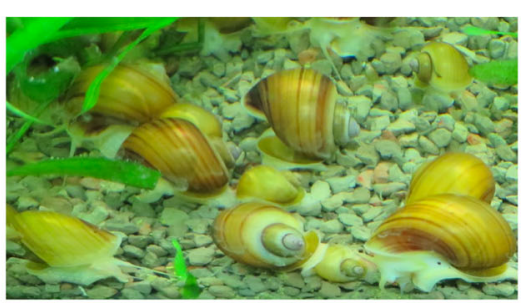

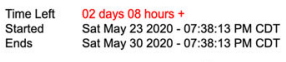

Seller
Location Edison NJ 08817 United States

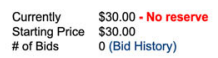

Q (View All Seller's Auctions or This Category)

(View Seller's Feedback)

(Search Feedback Forum about Seller)

(Ask Seller a Question)
(Report this Auction)

\section{High Bidder --}

Page Views 37

Payment See Item Description. PayPal

AquaBid.com doess not recommend payment via Western Union, Moneygram or other instant cash transfer services (non-bank, point-10-point cash transfors).

Effective Oct. 17, 2019: sellers are no longer allowed to request PayPal.com payments via the friend and family option. Shipping

Will Ship to Continental United States Only Buyer Pays Fixed Amount, See Item Description

Seller assumes all responsibility for listing this item. You should contact the seller to resolve any questions before bidding. Currency is U.S. dollars (US\$).

it Lise 0 Tweat Dint $51 \mathrm{~K}^{+}$

Description This auction is for 40 chestnut mystery snails. Pea size or up. They eat algae on plants, glass, etc. and fish food debris in gravel and also dead plants. They won't eat living plants and are
plant safe. They like to eat algae waters as shown in picture. These snails are living in a planted community tank with small fishes such as guppy, platy, molly, bristle nose pleco, cory cats an

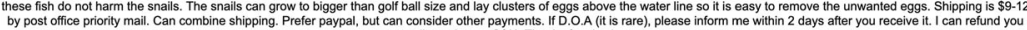
snail cost but no $S \& H$. Thanks for viewing.

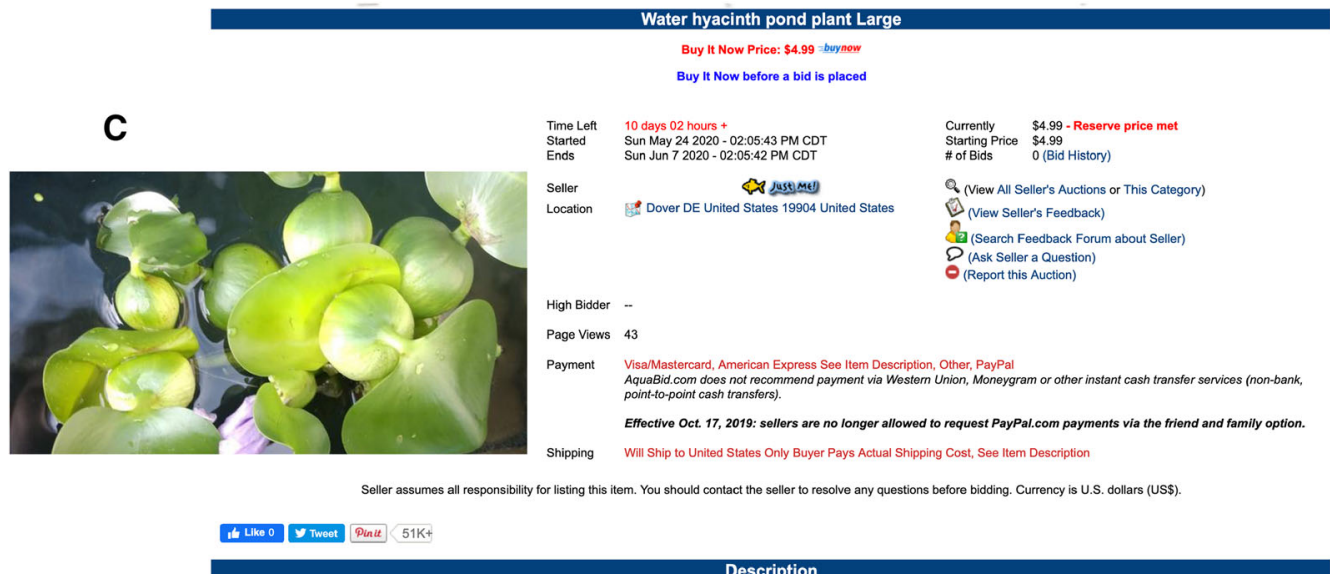

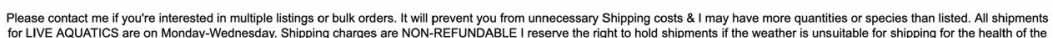
plant. My goal is to get your plants to you as fast as possible and in the best condition possible. II you have any problems with your order, please feel free to reach out I want you to have the best experience possible. Please, please contact me before opening a case or leaving negative feedback. I am a reasonable person and I try to make my customers happy. If you have Plants 
4Fig. 1 Screenshots of aquarium auction listings on AquaBid.com (May 28, 2020). Pictured are sales of A flowerhorn cichlid, $\mathbf{B}$ chestnut mystery snails, and $\mathbf{C}$ water hyacinth plant

the source location (sellers' location) and the destination location (buyers' location); these routes were visualized in chord diagrams produced using the circlize package in $\mathrm{R}$ version 3.5.1 ( $\mathrm{R}$ Core Team, 2016).

\section{Results}

Market dynamics

The AquaBid website documented the trade of live organisms among 24,409 unique users from 39 countries and 6 continents, who collectively placed 444,132 bids on 192,227 auctions over the 7-year study period. The mean number of bids for each auction was 2.3 ( $\mathrm{SD} \pm 3.1$ ) with a range of 1 to 60 bids. The market was diffuse with 3,287 sellers each holding an average market share by total auction value (USD) of $0.03 \%$ (SD \pm 0.12 ). Few sellers held prominent market shares in the marketplace with five users having market shares above $1 \%$.

An estimated 539,548 live animals, 579,700 killifish eggs, and 31,431 plant assortments/bunches were transported as part of completed auctions, representing a total value of $\$ 6,015,030$ USD. Annual completed auctions demonstrated an overall decreasing trend, but transaction values remained at over \$0.5 M USD each year. Average auction price was $\$ 31.30$ USD (SD \pm $\$ 49.08$ ) (Fig. 2), with a maximum of $\$ 6,000$ USD purchase price for a flowerhorn cichlid (Cichidae).

Plants assortments/bunches (16.4\%), killifish eggs (12.1\%), halfmoon and Plakat bettas (Betta splendens; Regan, 1910) (11.8\%, 8.6\%), guppies (Poecilia reticulata; W. Peters, 1859) (7.1\%) and invertebrates exclusively of snails $(6.9 \%)$ were the most purchased species categories by total auction count (Fig. 3A). Other noteworthy categories included a broad array of African and Central/South American cichlids, plecos (Hypostomus plecostomus; Linnaeus, 1758), catfishes (Corydoradinae), rainbow fish (Melanotaeniidae), "invertebrates" (mainly shrimp), and various "mixed lot" fishes and snails. Of particular note was 77 auctions for live Asian Arowanas (genus Scleropages), commonly known as "dragon fish" or "lucky fish", all by sellers in the US. Furthermore, a number of highly invasive species were being traded, including the common water hyacinth (Eichhornia crassipes; (Mart.) Solms) which appears on the IUCN list of the world's top 100 most invasive species (Fig. 1C). Total sale value (USD) largely mirrored patterns in total auctions, where the most commonly traded categories of organisms also held the largest share of the market (Fig. 3B). Notable exceptions included flowerhorn cichlids, discus cichlids (Cichidae) and freshwater stingrays (Potamotrygonidae); a result of these organisms fetching high sale prices. For example, flowerhorn cichlids and stingrays sold for an average price of $\$ 180.04$ and $\$ 547.47$ USD, respectively.

\section{Geography of trade}

Source (seller) and recipient (buyer) locations of auctions were distributed across 39 countries but concentrated largely in major cities of the US and scattered across select European and southeast Asian countries (Fig. 4). The transport of organisms occurred via 547 unique trade routes between sellers and buyers comprising a total of 37,727 auctions; a conservative representation based on $23 \%$ of all auctions (see "Methods" section, Fig. 5A). International trade of live organisms occurred in $22 \%$ of 37,727 auctions, involving a diffuse network of trading partners. Live organisms were predominantly traded from Europe to Asia and the US, and from Asia to the US (Fig. 5A). Major trade routes included those from Thailand/Malaysia and Poland to the US, Czech Republic/Bulgaria/Spain to China (limited to killifish eggs), and from numerous European countries to the UK (Fig. 5B). The average seller-to-buyer straightline distance that live organisms were shipped between different countries was $8,419 \mathrm{~km}$ (SD = $5,353 \mathrm{~km}$ ) with a maximum distance of $19,373 \mathrm{~km}$ between Japan and Brazil.

Trade routes within the US were the most prominent, totaling approximately $78 \%$ of 37,727 auctions (Fig. 5A). These auctions resulted in live organisms being transported within 1,867 trade routes between sellers and buyers of all states, District of Columbia and Puerto Rico. Trade in live organisms was extremely diffuse according to major regions of the US, although the most active trade predominantly 
Fig. 2 Frequency of 192,227 AquaBid auctions (\%) according to final sale price (USD) reported over the 7-year study period (2011-2017). Only sale prices lower than $\$ 250$ USD are shown (representing $99.5 \%$ of all auctions) to aid visualization

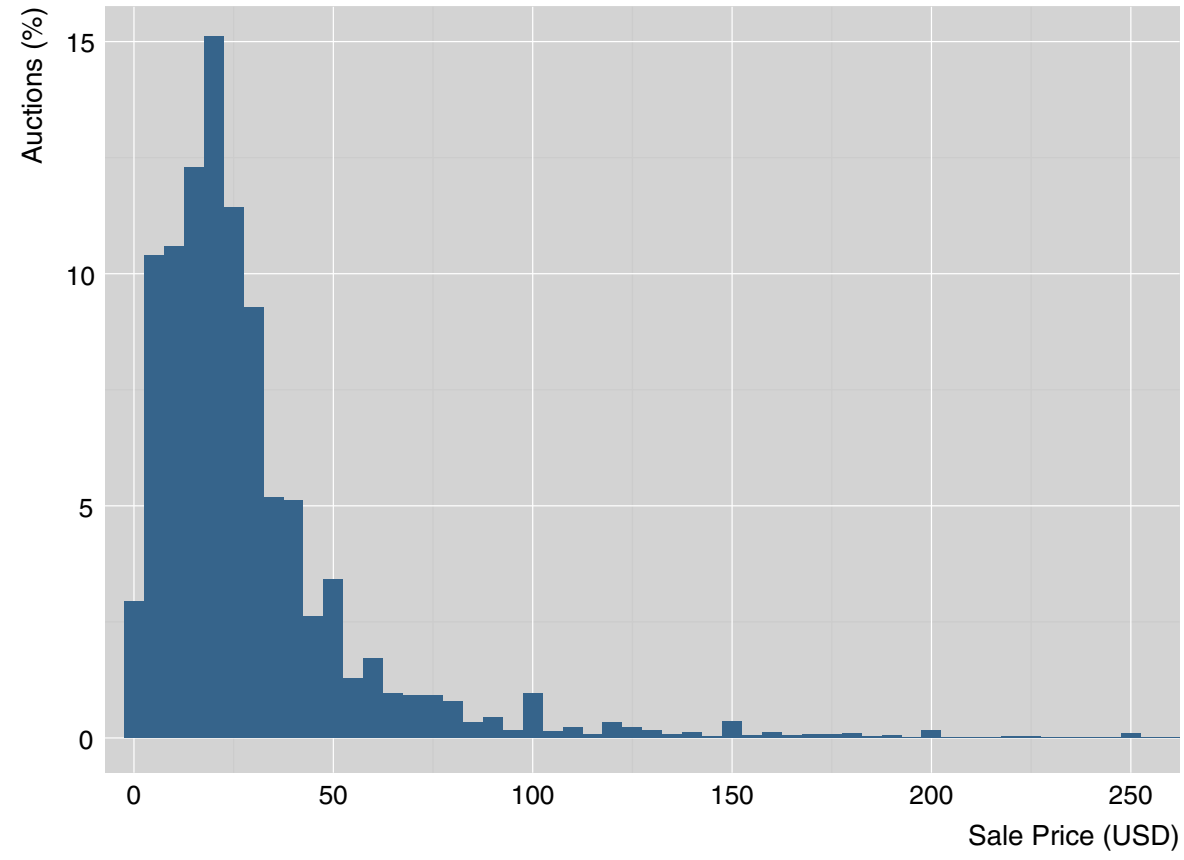

A

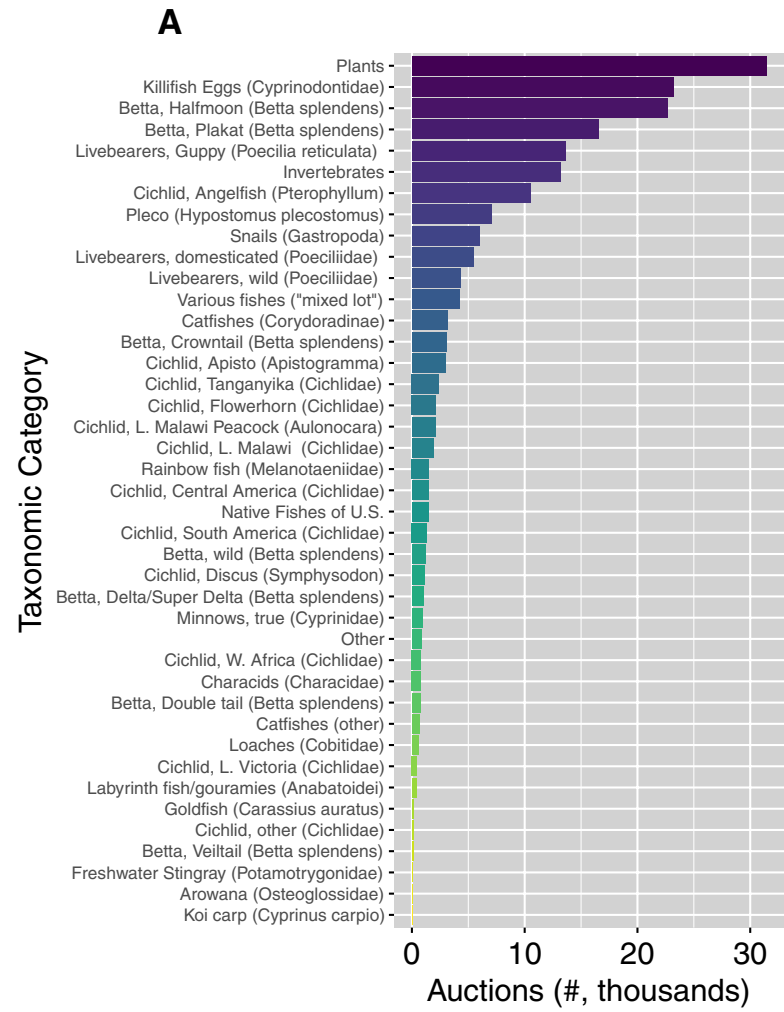

B

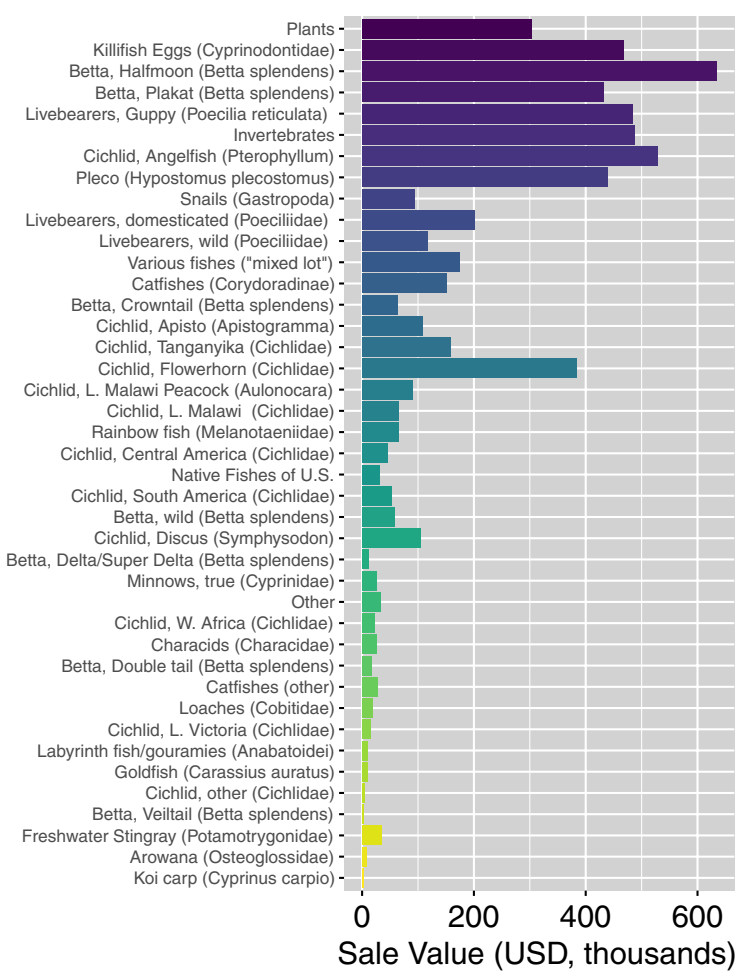

Fig. 3 Total A number and $\mathbf{B}$ sale value (USD) of AquaBid auctions according to major taxonomic category 


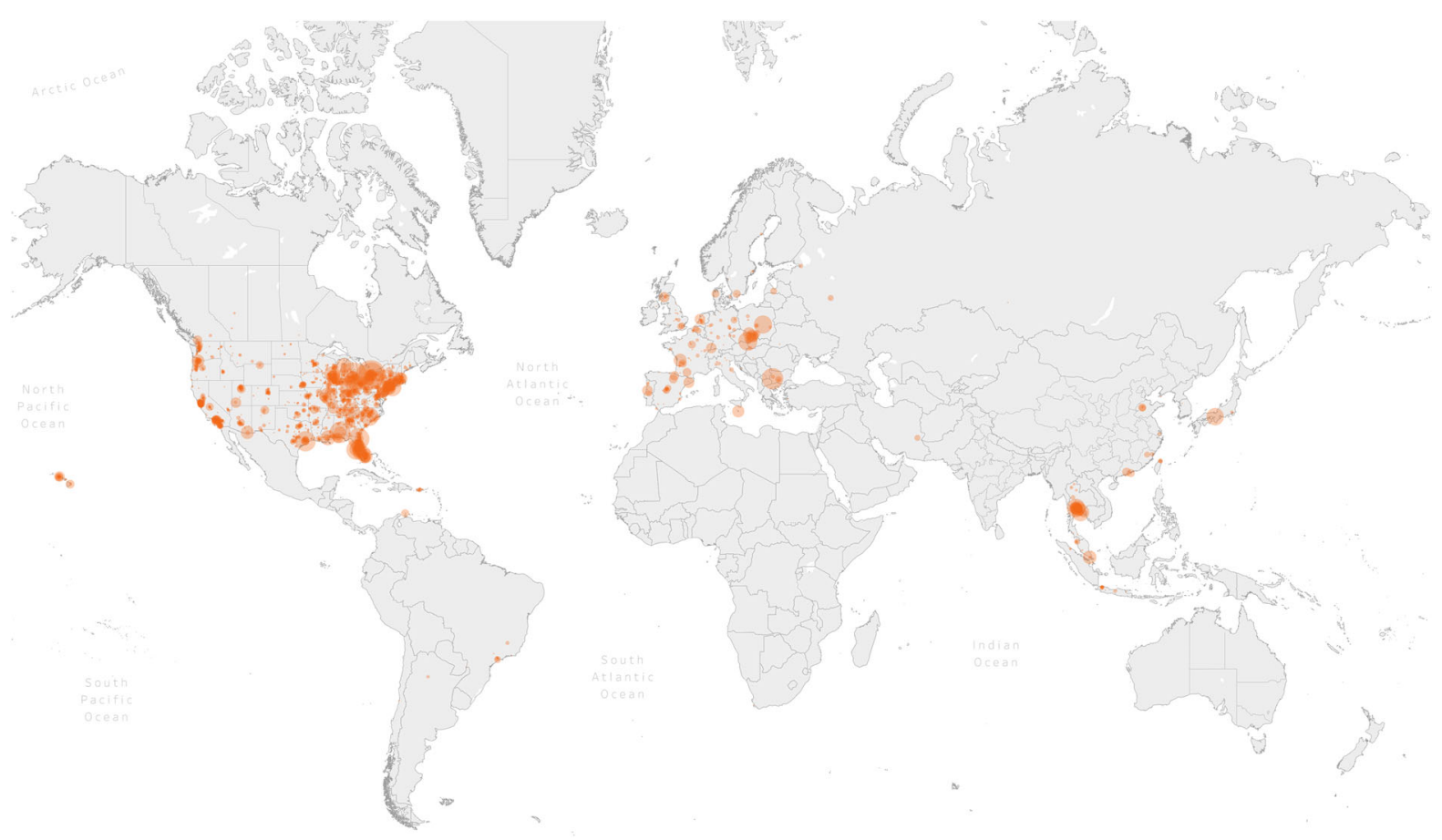

Fig. 4 Global distribution of sellers on AquaBid. Symbol size is scaled according to the total number of auctions over the study period (2011-2017) ranging from 1 to 861

involved individuals located in the South Atlantic, Mid-Atlantic, North-east Central and Pacific (Fig. 5C). For example, live organisms associated with auctions traded from the South Atlantic to both the Mid- and North-east Central regions were higher, proportionally, compared to other trade routes. The North-west region was predominantly the recipient of live organism trade, whereas the remaining regions were more balanced in the number of sellers and buyers. The average seller-to-buyer straight-line distance that live organisms were shipped with the US was $1,675 \mathrm{~km}(\mathrm{SD}=1,352 \mathrm{~km})$.

We found evidence for both diffuse and directional trading routes of live organisms. For example, withincountry auctions of cichlids were variable across the US but largely involved highly populated cities (Fig. 6A). By contrast, sellers of native fishes were predominantly located in Florida, resulting in large directional trade routes radiating northward to numerous states (Fig. 6B). Inter-country shipments of killifish eggs in Europe were highly dispersed but with concentrated hubs in Spain, Portugal and Bulgaria (Fig. 6C). Finally, sellers of B. splendens in South-east Asia were highly concentrated in Bangkok, Rayong and other areas of Thailand (Fig. 6D). Auction transactions can be fully explored using a web interface available at Online Resource 1.

\section{Discussion}

Recent decades have witnessed mounting efforts to establish evidence-based regulations to limit species invasions (McGeoch et al., 2016), yet continued globalization is leading to growing pathways for their introduction and heightened risk (Hulme, 2009). Recent surges in global e-commerce linked to Internet sales of aquarium organisms may be expanding or creating new pathways for nonnative species, yet numerous gaps exist in our understanding of informal online marketplaces (Walters et al., 2006; Keller \& Lodge, 2007; Humair et al., 2015; Magalhães et al., 2017). According to the largest online auction site dedicated to the aquarium hobby, AquaBid, we revealed that well over $1 \mathrm{M}$ live fish and fish eggs, and thousands of invertebrates and plant bunches were transported around the global over a 7-year period. This highly active marketplace, representing a total 

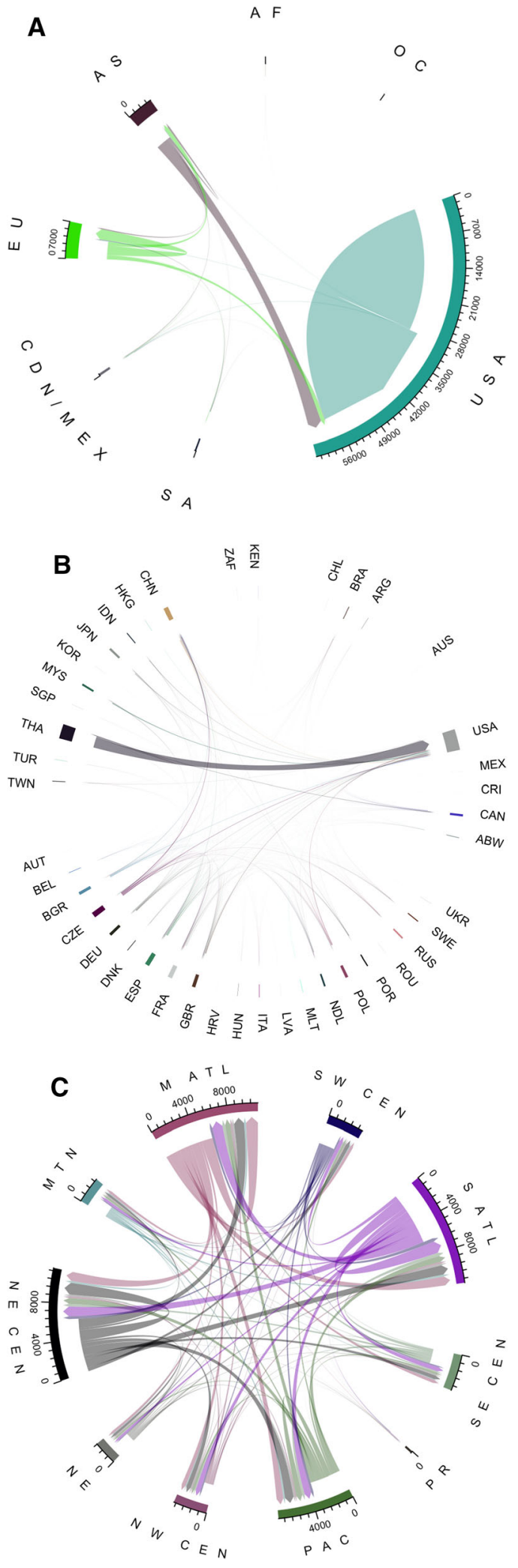

4Fig. 5 Number of AquaBid auction transactions among and within $\mathbf{A}$ continents, $\mathbf{B}$ countries, and $\mathbf{C}$ regions of the US, using chord diagrams. Transactions conducted within the US have been omitted from $\mathbf{B}$ to allow for better visualization of global transactions. The values on the circumference of each diagram represent the cumulative number of transactions. The thickness of chords represent the number of pairwise transactions between continents/countries/regions (chord colors differing from color on the outer ring) or within a continent/country/region (chord color the same as color on the outer ring), where sellers and buyers are denoted by the base and the head of the arrow, respectively. Continents include Asia (AS), Africa (AF), Europe (EU), North America separated according to the United States (USA) and Canada/Mexico (CDN/MEX), Oceania (OC), and South America (SA). Countries are labeled using ISO3 codes. Regions of the United States include Northeast (NE), NortheastCentral (NE CEN), Northwest-Central (NW CEN), Pacific (PAC), Puerto Rico (PR), Southeast-Central (SE CEN), SouthAtlantic (S ATL), Southwest-Central (SW CEN), Mid-Atlantic (M ATL) and Mountain (MTN)

sale value of over \$6 M USD, is an exemplar of the burgeoning aquatic trade supported by informal online marketplaces.

Online marketplaces provide access to a diversity of nonnative species that fulfill aquarists and consumers changing attitudes towards more convenient purchasing and the acquisition of specific, sometimes unusual, organisms for their aquaria (Humair et al., 2014; Marchio, 2018; Peres et al., 2018; Prokop \& Randler, 2018; Stringham \& Lockwood, 2018). Although it was challenging to identify organisms to the species level, the taxonomic category provided by sellers on auction postings revealed a wide diversity of organisms available for purchase. Buyers demonstrated a strong affinity towards halfmoon and Plakat bettas, guppies, cichlids, plecos, and rainbow fish. These popular fish species are commonly found in local pet stores and online (Strecker et al., 2011; Dey, 2016; Evers et al., 2019). The informal marketplace also contained species that are typically less available, including killifish (adults and eggs), arowanas, and particular types of African and Central/South American cichlids. Online marketplaces appear to provide a platform for aquarists to buy, sell and trade purebred cichlids that are not available from multinational or local pet stores who sell hybrid varieties. Other species on AquaBid which are not commonly available include Asian Arowanas, which are native to Southeast Asia and can grow to approximately $1 \mathrm{~m}$ in length, and the highly invasive common water hyacinth that 

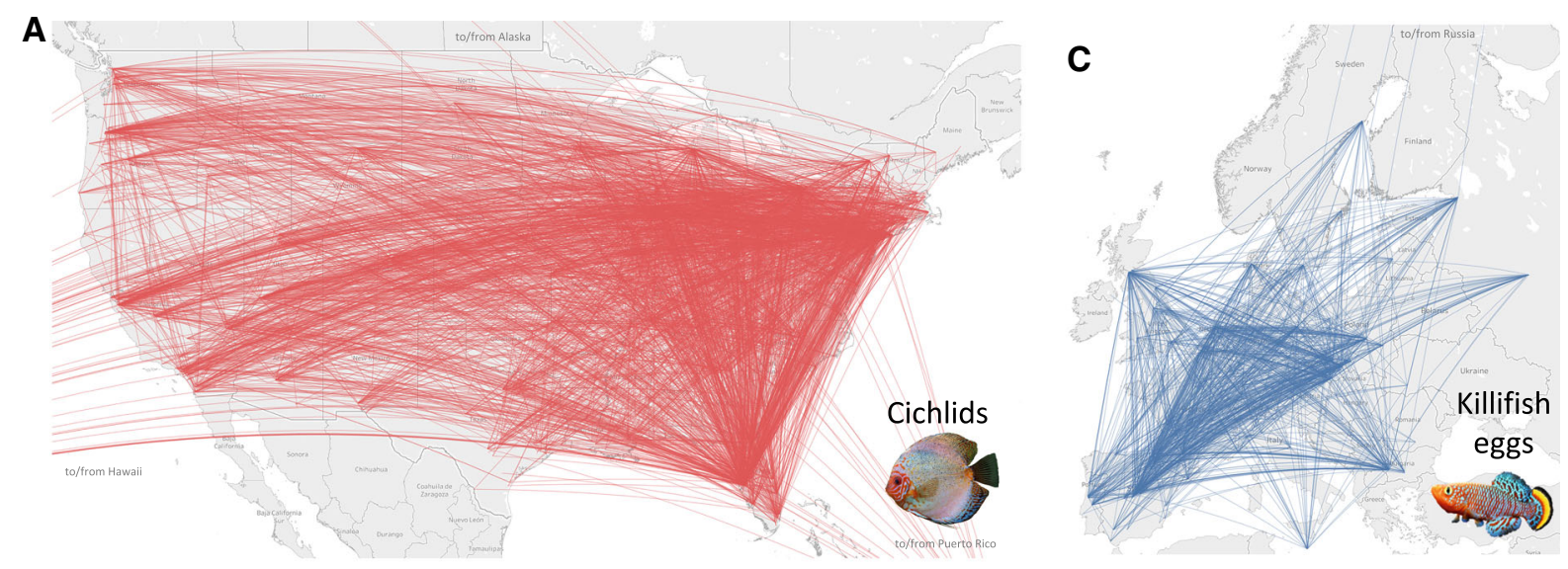

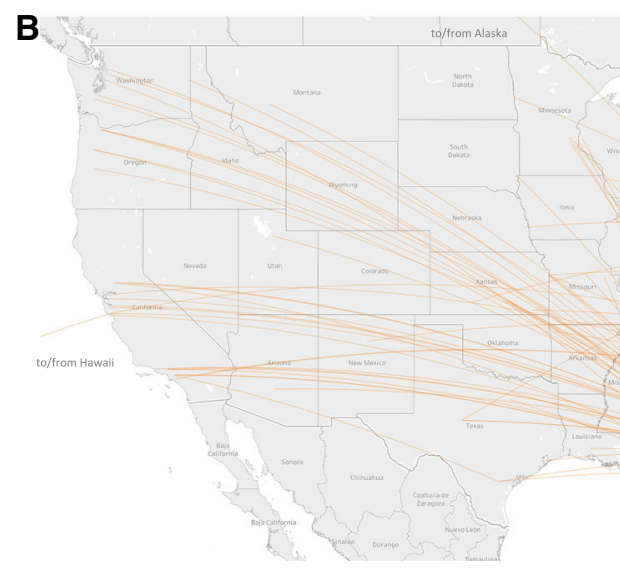

Fig. 6 Geographic routes of live organism shipments associated with A intra-country auctions of cichlids in the US, B intracountry auctions of native fishes in the US, $\mathbf{C}$ intra-continental

appears on the IUCN list of the world's top 100 most invasive species (Fig. 1C). Finally, the selling of various "mixed lot" fishes is also concerning because the taxonomic identity of these species is unclear from the auction listings (a similar challenge to live organism imports at borders: Smith et al., 2008) and may instead involve off-line discussions between buyers and sellers. The availability of both common and potentially unique species on informal marketplaces may be a significant risk factor in the introduction of nonnative aquatic species.

Our study revealed geographic routes of live organism transport between specific locations in 39 countries spanning six continents, thus demonstrating the highly diffuse and non-centralized nature of the informal aquarium trade. In a controlled study that compared the distance of organisms purchased instore and online, Lenda et al. (2014) found that organisms purchased online traveled six times farther
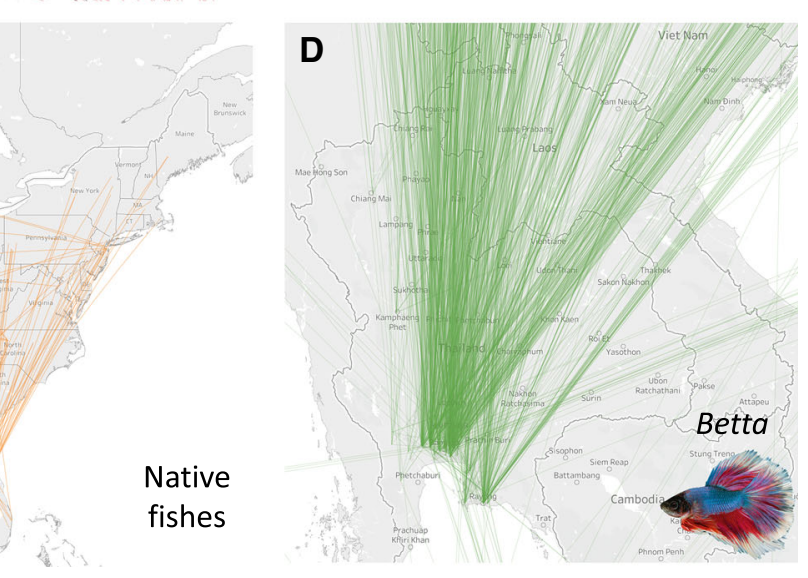

auctions of killifish eggs in Europe, and D auctions of Betta splendens exported from South-east Asia

than organisms purchased in-store; our results suggest that this disparity could be much larger with live organisms being shipped many thousands of kilometers around the world. Consequently, the informal marketplace could be an important contributor to longdistance dispersal pathways for nonnative species. Thailand was the largest exporter of shipments to the US followed by an array of other countries located in Asia and Europe. The prominence of Asia, and in particular Southeast Asia in the aquarium trade has been previously noted because of the diversity of species available in that region and high aesthetic value placed on them by aquarists (Padilla \& Williams, 2004; Rhyne et al., 2017; Evers et al., 2019; Pinnegar \& Murray, 2019). In addition to international trade, a significant number of auction transactions occurred between buyers and sellers in the US. This is perhaps not surprising since AquaBid is based in the US and thus challenges to shipping live organisms 
within the country are lower. The largest trade activities occurred among major cities in the MidAtlantic, South Atlantic and North-east Central regions, although trade linkages were evident across all states and territories. This supports the fact that the informal market creates an environment that enables consumers to purchase aquatic organisms without the deterrence of distance to factor into their decisionmaking, thus creating novel, and substantially longer pathways for the dispersal between disparate pools of nonnative species (Olden et al., 2018).

The diffuse nature of the informal aquarium trade creates challenges for biosecurity and invasive species policy of many countries. The minimal barriers to entry in the informal retail marketplace combined with its potential anonymity has facilitated the trade of prohibited aquatic species in many countries, including New Zealand, Brazil, and the UK (ISAC, 2012; Kikillus et al., 2012; Magalhães, 2015). Unlike traditional "brick-and-mortar" pet stores, the online market can more rapidly adapt to consumer preference by listing species that are rare and unique to the global marketplace. This rapid ability to list new species combined with established selling platforms allows informal e-commerce marketplaces to potentially contribute to the spread of nonnative species to new locations through accidental or intentional release of live organisms (i.e., aquarium dumping).

Online marketplaces provide rich opportunities to better understand the geography of live organism trade. First, item descriptions often include details regarding the type and number of organisms being sold. However, informal names accustomed to aquarists are used exclusively in auction postings, thus poising a challenge to using this data stream. The necessity of relying on broad self-reported taxonomic categories by sellers results in an opaque understanding of the specific species involved in trade, thus making it difficult to enforce regulations according to names of black-listed prohibited species. Second, sellers also described their preferred mode of shipment in auction postings, including the use of the United States Postal Service. The use of established mailing services to ship aquarium species purchased online is recognized to facilitate the long-distance dispersal of invasive species (Lenda et al., 2014; Magalhães et al., 2017; Gurjão et al., 2018). Understanding the primary methods of how organisms are transported within informal marketplaces can aid law enforcement and regulatory agencies to enact policies that target the most trafficked mail systems. Third, concomitant to the rise of informal retail auction sites has also been the expansion of online fora for aquarium enthusiasts to discuss topics concerning the aquarium hobby. These provide an arena for communication between like-minded individuals to discuss topics related to their hobbies and interests (Bargh \& McKenna, 2004). Online fora, including one hosted by AquaBid, provide yet another dimension of the informal retail market where knowledgeable consumers have the opportunity to acquire specific organisms, and sellers can provide new offerings to potentially shape market demand. Online fora facilitate direct interactions between sellers and buyers who potentially want to purchase organisms in an unregulated and untracked manner (Magalhães et al., 2017).

For individual hobbyists, collectors and breeders, it is easy to participate in online marketplaces, and the anonymity provided by auctions may be a mechanism that incentivizes users to offer organisms that are illegal or banned in certain states (Lockwood et al., 2019). The AquaBid website contains detailed information on buying and selling live organisms, yet at the time of this publication it only includes the following brief statement on illegal aquatic species: "Some states prohibit the movement, sale and/or distribution of various aquatic species. Please check with your local authorities" (last updated on 10/19/2007), in the Frequently Asked Questions section. This is followed by links to four US states that supposedly contain a list of prohibited species; two links are broken (Massachusetts, Washington), one link redirects to website not containing a list (Vermont), and the last link is to a list of nuisance plant species created in 2005 (Florida). Furthermore, an examination of the online community forum revealed comments and discussions on the trade of six prohibited fish species currently listed on the US Lacey Act. However, these postings also contained comments from users expressing concerns about the selling of prohibited species. This suggests that users may play an active role in educating others on the forum when a species listed for sale was invasive or prohibited in a US state. Regulators and law enforcement could utilize this peer-to-peer education in online fora by posting infomercials that detail species of primary concern to further educate the community of users present on online forums. 
Utilizing the data provided by aquarium enthusiasts and hobbyists in auction descriptions and online fora provides important insights into the consumer behavior and potential illicit trade of prohibited aquatic organisms. Further research should focus on emerging online platforms for aquarium enthusiasts including Facebook (policy prohibits selling of live animals but enforcement is largely lacking), Twitter, WhatsApp, and other aquarium fora to construct a broader understanding of consumer behavior and to identify species that will become popular within the aquarium trade (Humair et al., 2015; Magalhães et al., 2017). Extending to online platforms that are hosted outside of the US is also important. Applying text-mining techniques, image recognition algorithms and other social media tools (Feldman et al., 2008; Daume, 2016; Li et al., 2016) to auction descriptions and online fora may enable researchers to better understand consumer behavior and trends concerning the ornamental aquarium trade. Ultimately, such knowledge could support regulatory and enforcement agencies to more efficiently apply their resources in monitoring species of high concern.

The scale and diversity of the informal retail arrangements identified in this analysis highlights the difficulty in current biosecurity polices to intercept and seize invasive or potentially invasive species. Illegal importation via informal online marketplaces can occur in a number of ways. Previous lawenforcement investigations into AquaBid (and other websites) have found users willing to sell and ship prohibited species without required documentation, and in some cases, this has led to arrests (e.g., United States v. Danny Yep, No. 3:07-CR-00481, N.D. California). Another apparent mechanism for illegal importation is for sellers to ship live organisms to a trans-shipper in a nearby country where the fish were not banned, and then smuggle these shipments into the prohibiting country via ground transport to circumvent more rigorous inspection of international air shipments of live animals (ISAC, 2012). A study of marine ornamental fishes in Switzerland found that $30 \%$ of all imported specimens were trans-shipped to 11 other European countries (Biondo, 2018). Furthermore, sellers can ship living organisms directly using mail service (Morrisey et al., 2011) that, unlike express delivery, doesn't generally require any electronic declaration about the content of the packages. Finally, sellers can also falsely declare the contents of shipments on custom declaration forms to attempt to evade customs and wildlife inspectors (Humair et al., 2015). These methods have been used in Brazil where sellers of nonnative fish on informal retail markets have used a variety of methods to suppress the contents of their package to avoid being seized (Gurjão et al., 2018).

\section{Conclusion}

The informal marketplace created by AquaBid supports an active community of aquarists who participated in buying, selling, and bidding of live organisms. AquaBid was the first website dedicated to direct peerto-peer selling of organisms through auctions, and its presence among aquarium enthusiasts has created a large number of users. With the rise of AquaBid's active community, there has been a simultaneous expansion of informal retail across the internet with a yearly growth rate of $14 \%$ in the US alone (U.S. Department of Commerce, 2019) and a spike in growth starting in 2020 due to the COVID-19 pandemic. Consequently, there is a need to analyze emerging informal markets, as well as countless other online platforms, to quantify their contribution to the trade of aquarium organisms.

This study aimed to raise awareness of the global extent of the informal e-commence marketplace for aquatic invasive species. Trade via the internet is largely unregulated, therefore, national policies are critical to effectively manage this invasive species pathway. Recent recommendations call for "white" (allowed in trade) or "black" lists (not allowed in trade) of regulated species that are easily accessible to all relevant parties (sellers, buyers, platforms, custom organizations, natural resource agencies, environmental protection agencies). It is important to collaborate closely with the leading e-commence companies to prevent the posting of auctions involving restricted species, improve the taxonomic information listed in auctions, and provide warnings and other information regarding existing regulations (Monaco, 2019). Additionally, web tools and required reporting by companies would allow for monitoring those species currently traded in online marketplaces and allow for anticipating changing seller and buyer preferences. Looking to the future, it is abundantly clear that additional scrutiny is needed to support biosecurity 
polices that consider the diffuse nature of the e-commence trade in live organisms.

Acknowledgements We thank two anonymous reviewers for their comments that improved the manuscript. EW was supported by the W.F. Thompson Scholarship awarded by the School of Aquatic and Fishery Sciences at the University of Washington. EW would like to thank Thiago Couto, Jane Rogosch and Rebekah Stiling for their support and advice throughout this project. This work was supported by a Data Science Environments Project Award from the Gordon and Betty Moore Foundation (Award \#2013-10-29) and the Alfred P. Sloan Foundation (Award \#3835) to the University of Washington eScience Institute.

\section{References}

American Pet Products Association, APPA, 2017. Pet Industry Market Size: Ownership. American Pet Products Association

Bargh, J. A. \& K. Y. A. McKenna, 2004. The Internet and social life. Annual Review of Psychology: Annual Reviews 55: 573-590.

Biondo, M. V., 2018. Importation of marine ornamental fishes to Switzerland. Global Ecology and Conservation 15: e00418.

Chan, F. T., S. J. Beatty, A. S. Gilles Jr., J. E. Hill, S. Kozic, D. Luo, D. L. Morgan, R. T. B. Pavia Jr., T. W. Therriault, H. Verreycken, L. Vilizzi, H. Wei, D. C. J. Yeo, Y. Zeng, G. Zięba \& G. H. Copp, 2019. Leaving the fish bowl: the ornamental trade as a global vector for freshwater fish invasions. Aquatic Ecosystem Health and Management 22: 417-439.

Chang, A. L., J. D. Grossman, T. S. Spezio, H. W. Weiskel, J. C. Blum, J. W. Burt, A. A. Muir, J. Piovia-Scott, K. E. Veblen \& E. D. Grosholz, 2009. Tackling aquatic invasions: risks and opportunities for the aquarium fish industry. Biological Invasions 11: 773-785.

Chucholl, C., 2013. Invaders for sale: trade and determinants of introduction of ornamental freshwater crayfish. Biological Invasions 15: 125-141.

Cohen, J., N. Mirotchnick \& B. Leung, 2007. Thousands introduced annually: the aquarium pathway for nonindigenous plants to the St Lawrence Seaway. Frontiers in Ecology and the Environment 5: 528-532.

Daume, S., 2016. Mining Twitter to monitor invasive alien species - an analytical framework and sample information topologies. Ecological Informatics 31: 70-82.

Derraik, J. G. B. \& S. Phillips, 2010. Online trade poses a threat to biosecurity in New Zealand. Biological Invasions 12: 1477-1480.

Dey, V. K., 2016. The global trade in ornamental fish. INFOFISH International 4: 52-55.

Duggan, I. C., C. A. M. Rixon \& H. J. MacIsaac, 2006. Popularity and propagule pressure: determinants of introduction and establishment of aquarium fish. Biological Invasions 8: 377-382.
Early, R., B. A. Bradley, J. S. Dukes, J. J. Lawler, J. D. Olden, D. M. Blumenthal, P. Gonzalez, E. D. Grosholz, I. Ibañez, L. P. Miller, C. J. B. Sorte \& A. J. Tatem, 2016. Global threats from invasive alien species in the twenty-first century and national response capacities. Nature Communications 7: 12485.

Evers, H. G., J. K. Pinnegar \& M. I. Taylor, 2019. Where are they all from? Sources and sustainability in the ornamental freshwater fish trade. Journal of Fish Biology 94: 909-916.

Feldman, R., M. Fresko, J. Goldenberg, O. Netzer \& L. Ungar, 2008. Using text mining to analyze user forums. In 5th International Conference Service Systems and Service Management - Exploring Service Dynamics with Science and Innovative Technology, ICSSSM'08.

Gertzen, E., O. Familiar \& B. Leung, 2008. Quantifying invasion pathways: fish introductions from the aquarium trade. Canadian Journal of Fisheries and Aquatic Sciences 65: 1265-1273.

Giltrap, N., D. Eyre \& P. Reed, 2009. Internet sales of plants for planting - an increasing trend and threat? EPPO Bulletin 39(2): 168-170.

Gurjão, L. M., G. M. L. Barros, D. P. Lopes, D. A. N. Machado \& T. M. C. Lotufo, 2018. Illegal trade of aquarium species through the Brazilian postal service in Ceará State. Marine and Freshwater Research 69: 178-185.

Hulme, P. E., 2009. Trade, transport and trouble: managing invasive species pathways in an era of globalization. Journal of Applied Ecology 46: 10-18.

Humair, F., C. Kueffer \& M. Siegrist, 2014. Are non-native plants perceived to be more risky? Factors influencing horticulturists' risk perceptions of ornamental plant species. PLoS ONE 9: e102121.

Humair, F., L. Humair, F. Kuhn \& C. Kueffer, 2015. E-commerce trade in invasive plants. Conservation Biology 29: $1658-1665$.

Invasive Species Advisory Committee, 2012. Invasive Species and e-Commerce. Invasive Species Advisory Committee, Washington, DC.

Kay, S. H. \& S. T. Hoyle, 2001. Mail order, the Internet, and invasive aquatic weeds. Journal of Aquatic Plant Management 39: 88-91.

Keller, R. P. \& D. M. Lodge, 2007. Species invasions from commerce in live aquatic organisms: problems and possible solutions. BioScience 57: 428-436.

Kikillus, K. H., K. M. Hare \& S. Hartley, 2012. Online trading tools as a method of estimating propagule pressure via the pet-release pathway. Biological Invasions 14: 2657-2664.

Lenda, M., P. Skórka, J. M. H. Knops, D. Moroń, W. J. Sutherland, K. Kuszewska \& M. Woyciechowski, 2014. Effect of the internet commerce on dispersal modes of invasive alien species. PLoS ONE 9: e99786.

Li, W., H. Chen \& J. F. Nunamaker, 2016. Identifying and profiling key sellers in cyber carding community: AZSecure Text Mining System. Journal of Management Information Systems 33: 1059-1086.

Lockwood, J. L., D. J. Welbourne, C. M. Romagosa, P. Cassey, N. E. Mandrak, A. Strecker, B. Leung, O. C. Stringham, B. Udell, D. J. Episcopio-Sturgeon, M. F. Tlusty, J. Sinclair, M. R. Springborn, E. F. Pienaar, A. L. Rhyne \& R. Keller, 2019. When pets become pests: the role of the exotic pet 
trade in producing invasive vertebrate animals. Frontiers in Ecology and the Environment 17: 323-330.

Maceda-Veiga, A., J. Escribano-Alacid, A. de Sostoa \& E. García-Berthou, 2013. The aquarium trade as a potential source of fish introductions in southwestern Europe. Biological Invasions 15: 2707-2716.

Magalhães, A. L. B., 2015. Presence of prohibited fishes in the Brazilian aquarium trade: effectiveness of laws, management options and future prospects. Journal of Applied Ichthyology 31: 170-172.

Magalhães, A. L. B. \& C. M. Jacobi, 2010. E-commerce of freshwater aquarium fishes: potential disseminator of exotic species in Brazil. Acta Scientiarum Biological Sciences 32: 243-248.

Magalhães, A. L. B. \& C. M. Jacobi, 2013. Invasion risks posed by ornamental freshwater fish trade to southeastern Brazilian rivers. Neotropical Ichthyology 11: 433-441.

Magalhães, A. L. B. \& C. M. Jacobi, 2017. Colorful invasion in permissive Neotropical ecosystems: establishment of ornamental non-native poeciliids of the genera Poecilia/ Xiphophorus (Cyprinodontiformes: Poeciliidae) and management alternatives. Neotropical Ichthyology 15: e160094.

Magalhães, A. L. B., M. L. Orsi, F. M. Pelicice, V. M. AzevedoSantos, J. R. S. Vitule, D. P. Lima-Junior \& M. F. G. Brito, 2017. Small size today, aquarium dumping tomorrow: sales of juvenile non-native large fish as an important threat in Brazil. Neotropical Ichthyology 15: e170033.

Maki, K. \& S. Galatowitsch, 2004. Movement of invasive aquatic plants into Minnesota (USA) through horticultural trade. Biological Conservation 118: 389-396.

Marchio, E. A., 2018. The art of aquarium keeping communicates science and conservation. Frontiers in Communication 3: 17 .

Martin, G. D. \& J. A. Coetzee, 2011. Pet stores, aquarists and the internet trade as modes of introduction and spread of invasive macrophytes in South Africa. Water SA Water Research Commission 37: 371-380.

Mazza, G., L. Aquiloni, A. F. Inghilesi, C. Giuliani, L. Lazzaro, G. Ferretti, L. Lastrucci, B. Foggi \& E. Tricarico, 2015. Aliens just a click away: the online aquarium trade in Italy. Management of Biological Invasions 6: 253-261.

McGeoch, M. A., P. Genovesi, P. J. Bellingham, M. J. Costello, C. McGrannachan \& A. Sheppard, 2016. Prioritizing species, pathways, and sites to achieve conservation targets for biological invasion. Biological Invasions 18: 299-314.

Monaco, A., 2019. Guidance Document on E-commence and IAS. Convention on the Conservation of European Wildlife and Natural Habitats, Strasbourg, 3-6 December, 2019.

Morrisey, D., G. Inglis, K. Neil, A. Bradley \& I. Fitridge, 2011. Characterization of the marine aquarium trade and management of associated marine pests in Australia, a country with stringent import biosecurity regulation. Environmental Conservation 38: 89-100.

Ng, T. H., S. K. Tan, W. H. Wong, R. Meier, S. Y. Chan, H. H. Tan \& D. C. J. Yeo, 2016. Molluscs for sale: assessment of freshwater gastropods and bivalves in the ornamental pet trade. PLoS ONE 11: e0161130.

Olden, J. D., L. Comte \& X. Giam, 2018. The Homogocene: a research prospectus for the study of biotic homogenization. NeoBiota 37: 23-36.
Padilla, D. K. \& S. L. Williams, 2004. Beyond ballast water: aquarium and ornamental trades as sources of invasive species in aquatic ecosystems. Frontiers in Ecology and the Environment 2: 131-138.

Papavlasopoulou, I., C. Perdikaris, L. Vardakas \& I. Paschos, 2014. Enemy at the gates: introduction potential of nonindigenous freshwater crayfish in Greece via the aquarium trade. Central European Journal of Biology 9: 11-18.

Peres, C. K., R. W. Lambrecht, D. A. Tavares \& W. A. Chiba de Castro, 2018. Alien express: the threat of aquarium e-commerce introducing invasive aquatic plants in Brazil. Perspectives in Ecology and Conservation 16: 221-227.

Pinnegar, J. K. \& J. M. Murray, 2019. Understanding the United Kingdom marine aquarium trade - a mystery shopper study of species on sale. Journal of Fish Biology 94: 917-924.

Prokop, P. \& C. Randler, 2018. Biological predispositions and individual differences in human attitudes toward animals. In Ethnozoology: Animals in Our Lives: 447-466. https:// doi.org/10.1016/B978-0-12-809913-1.00023-5.

R Core Team, 2016. R: A Language and Environment for Statistical Computing. Version 3.5.1. R Foundation for Statistical Computing, Vienna.

Rhyne, A. L., M. F. Tlusty, J. T. Szczebak \& R. J. Holmberg, 2017. Expanding our understanding of the trade in marine aquarium animals. PeerJ 2017: e2949.

Rixon, C. A. M., I. C. Duggan, N. M. N. Bergeron, A. Ricciardi \& H. J. MacIsaac, 2005. Invasion risks posed by the aquarium trade and live fish markets on the Laurentian Great Lakes. Biodiversity and Conservation 14: 1365-1381.

Smith, K. F., M. D. Behrens, L. M. Max \& P. Daszak, 2008. U.S. drowning in unidentified fishes: scope, implications, and regulation of live fish import. Conservation Letters 1: 103-109.

Strecker, A. L., P. M. Campbell \& J. D. Olden, 2011. The aquarium trade as an invasion pathway in the Pacific Northwest. Fisheries 36: 74-85.

Stringham, O. C. \& J. L. Lockwood, 2018. Pet problems: biological and economic factors that influence the release of alien reptiles and amphibians by pet owners. Journal of Applied Ecology 55: 2632-2640.

Turbelin, A. J., B. D. Malamud \& R. A. Francis, 2017. Mapping the global state of invasive alien species: patterns of invasion and policy responses. Global Ecology and Biogeography 26: 78-92.

U.S. Department of Commerce, 2019. Quarterly Retail E-commence Sales 2019 [available on internet at http:// www.census.gov/retail]. Accessed August 1, 2020.

Walters, L. J., K. R. Brown, W. T. Stam \& J. L. Olsen, 2006. E-commerce and Caulerpa: unregulated dispersal of invasive species. Frontiers in Ecology and the Environment 4: 75-79.

Weigle, S. M., L. D. Smith, J. T. Carlton \& J. Pederson, 2005. Assessing the risk of introducing exotic species via the live marine species trade. Conservation Biology 19: 213-223.

Publisher's Note Springer Nature remains neutral with regard to jurisdictional claims in published maps and institutional affiliations. 